\title{
Aprendizagem Colaborativa no Contexto de uma Atividade de Modelagem Matemática
}

\author{
Collaborative Learning in the Context of a Mathematical Modeling \\ Activity
}

\author{
Adriana Helena Borssoi* \\ ORCID iD 0000-0002-1725-6307 \\ Karina Alessandra Pessoa da Silva** \\ ORCID iD 0000-0002-1766-137X \\ Elaine Cristina Ferruzzi ${ }^{* * *}$ \\ ORCID iD 0000-0003-3378-5185
}

\begin{abstract}
Resumo
Neste artigo nos concentramos em investigar o que se mostra de aprendizagem colaborativa quando os alunos, em grupos, desenvolvem uma atividade de Modelagem Matemática. Para isso, analisamos uma atividade desenvolvida por um grupo de alunos de um curso de Licenciatura em Química na disciplina de Equações Diferenciais Ordinárias. A análise qualitativa de cunho interpretativo dos registros escritos, áudios e vídeos está pautada em aspectos da aprendizagem colaborativa, quais sejam: interatividade, sincronia na interação e negociação. Com isso, pudemos inferir que, quando os alunos são orientados a trabalhar colaborativamente, de maneira a aprender juntos, se fazer entender, ouvir outras vozes e negociar encaminhamentos, seja para entendimento e simplificação da situação problemática, para matematização ou para determinar a solução, a aprendizagem colaborativa é oportunizada.
\end{abstract}

Palavras-chave: Modelagem Matemática. Aprendizagem Colaborativa. Trabalho em Grupo. Interações. Equações Diferenciais Ordinárias.

\begin{abstract}
In this paper, we focus on investigating what presents itself of the collaborative learning when students, in groups, develop a mathematical modeling activity. For that, we analyzed an activity developed by a group of students of a Chemistry Degree course in the discipline of Ordinary Differential Equations. The qualitative

\footnotetext{
* Doutora em Ensino de Ciências e Educação Matemática pela Universidade Estadual de Londrina (UEL). Docente do Departamento Acadêmico de Matemática e do Programa de Pós-Graduação em Ensino de Matemática da Universidade Tecnológica Federal do Paraná (UTFPR), Londrina, Paraná, Brasil. E-mail: adrianaborssoi@utfpr.edu.br.

${ }^{* *}$ Doutora em Ensino de Ciências e Educação Matemática pela Universidade Estadual de Londrina (UEL). Docente do Departamento Acadêmico de Matemática e do Programa de Pós-Graduação em Ensino de Matemática da Universidade Tecnológica Federal do Paraná (UTFPR), Londrina, Paraná, Brasil. E-mail: karinasilva@utfpr.edu.br.

*** Doutora em Ensino de Ciências e Educação Matemática pela Universidade Estadual de Londrina (UEL). Docente do Departamento Acadêmico de Matemática e do Programa de Pós-Graduação em Ensino de Matemática da Universidade Tecnológica Federal do Paraná (UTFPR), Londrina, Paraná, Brasil. E-mail: elaineferruzzi@utfpr.edu.br.
} 
analysis of the interpretative nature of the written records, audios, and videos is based on aspects of collaborative learning, namely: interactivity, synchrony in interaction, and negotiation. With that, we could infer that, when students are oriented to work collaboratively, to learn together, to make themselves understood, to hear other voices and negotiate referrals, either to understand and simplify the problematic situation, to mathematize or to determine the solution, we achieve collaborative learning.

Keyword: Mathematical modeling. Collaborative learning. Group work. Interactions. Ordinary Differential Equations.

\section{Introdução}

A aprendizagem no ambiente educacional tem despertado interesse em profissionais de diferentes áreas. Ao tratarmos da aprendizagem, levamos em consideração um processo no qual o aluno internaliza conceitos a partir de experiências e de interações. Embora aprender seja essencialmente ação do indivíduo que aprende, nosso entendimento está pautado no fato de a aprendizagem ser oportunizada na " [...] interação desse indivíduo com os outros, sejam eles os colegas, o professor, um livro, ou até mesmo 'vozes' advindas de experiências anteriores que ecoam em sua mente" (VERTUAN; BORSSOI; ALMEIDA, 2013, p. 64).

Neste artigo, assumimos a interação como um discurso interativo, ou seja, aquele que envolve no mínimo duas pessoas e, conforme Mortimer e Scott (2002), em que existe uma troca de turnos nas falas.

Não é a interação por si só que faz com que os sujeitos aprendam, mas, de acordo com Dillenbourg (1999, p. 5), “a interação entre os sujeitos gera atividades extras (explicação, desacordo, regulação mútua, ...) que desencadeiam mecanismos cognitivos extras (elicitação de conhecimento, internalização, carga cognitiva reduzida, ...)”. Para o autor, a cognição individual não é suprimida na interação entre pares e o aprender pode ser favorecido em situações de colaboração.

O que nos move em nossas investigações diz respeito à aprendizagem dos alunos e às formas de oportuniza-las, no entanto, neste artigo o foco do estudo não está na aprendizagem dos alunos, mas sim em reflexões sobre aprendizagem colaborativa como um constructo para aulas de Matemática quando os alunos trabalham em grupo.

Para Torres (2007, p. 339), a "aprendizagem colaborativa pode ser definida como uma metodologia de aprendizagem na qual, por meio do trabalho em grupo e pela troca entre os pares, as pessoas envolvidas no processo aprendem juntas". O sucesso do grupo está intrinsecamente associado ao envolvimento de cada um dos integrantes. O professor tem 
como função estimular a participação e interação dos alunos.

Dentre as tendências da Educação Matemática, a Modelagem Matemática tem o trabalho em grupo como um aporte. Levando em consideração que em atividades de Modelagem busca-se uma solução para um problema geralmente originário fora do contexto matemático (ALMEIDA, 2010), entendemos que, em aulas de Matemática, seu desenvolvimento possibilita a compreensão do fenômeno em estudo, ao mesmo tempo em que se aprende Matemática. Essa aprendizagem, de certa forma, ocorre com a participação entre pares - professor e alunos e alunos e alunos.

Embora na literatura encontremos pesquisas que associam o desenvolvimento de atividades de Modelagem em sala de aula e o trabalho colaborativo (ÄRLEBÄCK; DOERR, 2018; BROWN; IKEDA, 2019; NAFTALIEV, 2017), em geral não é evidenciado metodologicamente como as pesquisas caracterizam a colaboração, o trabalho colaborativo, a aprendizagem colaborativa. A investigação que realizamos está inserida em um projeto de pesquisa que leva em consideração a configuração de um ambiente educacional em que atividades colaborativas se fazem presentes. O que intentamos neste artigo é trazer reflexões sobre o que se mostra de aprendizagem colaborativa quando os alunos, trabalhando em grupo, entendem e simplificam a situação problemática, realizam matematização e obtêm uma solução no desenvolvimento de uma atividade de Modelagem Matemática. Para isso, nos fundamentamos nos aspectos da aprendizagem colaborativa de Correa (2000), quais sejam interatividade e sincronia na interação e negociação.

Os dados que subsidiam nossas análises advêm de uma atividade de Modelagem desenvolvida por um grupo de alunos de um curso de Licenciatura em Química na disciplina de Equações Diferenciais Ordinárias (EDO).

Para apresentar os resultados de nossa investigação organizamos este texto em quatro seções subsequentes. Na primeira, descrevemos o ambiente educacional investigado e como ocorreu a opção pela implementação de uma atividade de Modelagem Matemática em sala de aula. Nas duas seções seguintes, apresentamos o quadro teórico relativo à Modelagem Matemática na Educação Matemática e à aprendizagem colaborativa. Em seguida, trazemos as análises da atividade desenvolvida. Finalizamos com algumas considerações sobre nossa investigação. 


\section{0 ambiente educacional investigado e a opção pela Modelagem Matemática}

Ambiente educacional pode se constituir em um espaço físico e/ou virtual que tem impacto no rendimento acadêmico dos estudantes e, nesse sentido, deve ser investigado e aprimorado com o objetivo de aperfeiçoar o processo educacional (TRONCON, 2014).

Com o intuito de desenvolver uma atividade avaliativa, um ambiente educacional se configurou no âmbito da disciplina de Equações Diferenciais Ordinárias de três cursos de graduação de uma universidade pública do Paraná. Setenta alunos distribuídos em três turmas participaram da primeira proposição de uma atividade avaliativa constituída no ambiente virtual. Dentre outras questões que os alunos deveriam responder constava uma situaçãoproblema que fora formulada de duas formas diferentes.

$\mathrm{Na}$ primeira formulação, os alunos deveriam interpretar qual dos gráficos apresentados corresponderia à situação-problema enunciada e bastava selecionar a alternativa que considerassem adequada.

Com a segunda formulação (Figura 1), esperava-se que os alunos, a partir da interpretação da situação-problema, expressassem, por meio da Matemática, diferentes problemas de valor inicial (PVI) e o processo de matematização para identificar a constante de proporcionalidade necessária para a simulação da situação. Por se tratar de uma questão aberta, os alunos dispunham de um espaço para inserção de textos ou imagens, bem como tinham a possibilidade de anexar arquivos.

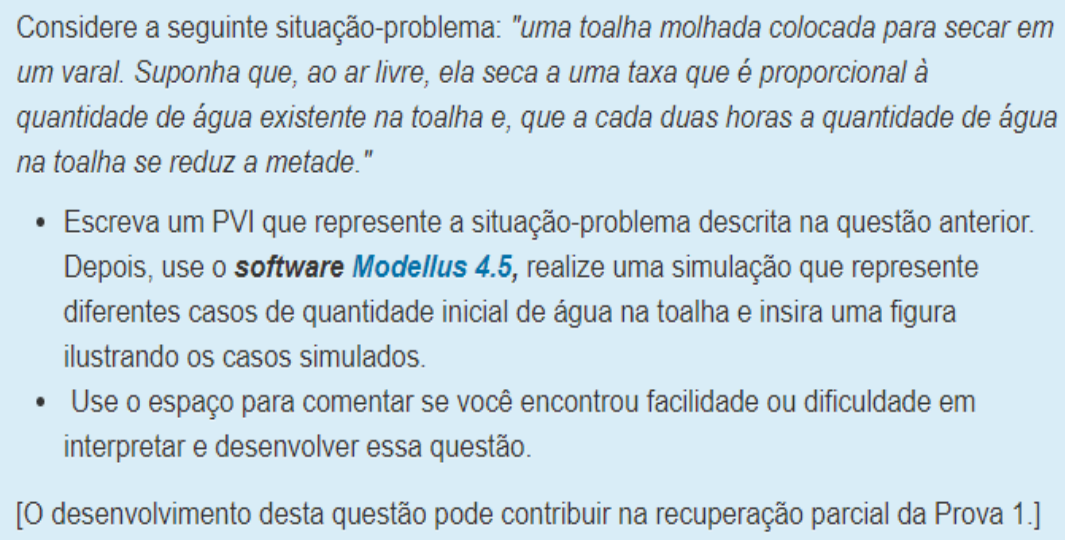

Figura 1 - Segunda formulação da situação-problema da atividade avaliativa de EDO de $1^{\mathrm{a}}$ ordem Fonte: Ambiente Virtual de Ensino e Aprendizagem (AVEA) da disciplina, no MOODLE (2018)

Neste artigo, discutimos o desdobramento provocado por reflexões da professora, uma das autoras, ao analisar os resultados das duas formulações para a turma do curso de Licenciatura em Química, composta por doze alunos. Embora na primeira formulação 
(quando bastava escolher o gráfico que representava a situação-problema), quase todos os alunos tenham acertado a alternativa correta, de modo geral, os alunos dessa turma não foram bem sucedidos em interpretar e resolver a segunda formulação (três apresentaram desenvolvimento satisfatório, seis insatisfatórios e três não responderam).

Assim, tratar da situação-problema por meio da Modelagem foi opção da professora, que intuiu que uma atividade de Modelagem Matemática poderia oportunizar aos alunos um envolvimento diferente daquele da primeira proposição, pois, a partir de dados reais poderiam compreender o fenômeno e simplificá-lo a ponto de fazer uma interpretação matemática de maneira a entender a situação-problema a ser resolvida. Além disso, por se tratar de uma turma de um curso de formação de professores, pretendia-se instigar aculturação dos futuros professores para a aprendizagem colaborativa, pois, como salientam Brown e Ikeda (2019), o trabalho em grupos colaborativos pode melhorar as oportunidades de solução bem-sucedida em uma atividade, mas, para isso, os alunos precisam aprender a trabalhar em grupo e a trabalhar em colaboração.

Nesse sentido, a turma foi organizada em três grupos (A, B e C), cuja composição foi prerrogativa da professora e teve a ciência dos alunos, considerando orientações de referenciais sobre aprendizagem colaborativa quanto a composição de grupos heterogêneos, no sentido de considerar alunos com habilidades altas, médias e baixas (CORREA, 2000). No caso, as diferentes habilidades foram ponderadas em relação ao que os alunos haviam demonstrado (ou não) em relação à primeira proposição. Cada grupo tinha como integrante um aluno que havia desenvolvido satisfatoriamente, ao menos um aluno que mostrou desenvolvimento parcialmente satisfatório e um aluno que não desenvolveu a questão aberta (segunda formulação).

Levando em consideração o que apregoa o quadro teórico em termos da interatividade, sincronia na interação e negociação, evidenciadas a partir do envolvimento dos alunos com a atividade de Modelagem, elegemos os dados do Grupo B para subsidiar nossas análises. Os cinco alunos desse grupo são designados ao longo do texto pelas letras E, F, J, R e T. A professora é referenciada pela letra P.

Para evidenciar o que se mostra de aprendizagem colaborativa no desenvolvimento de uma atividade de modelagem, consideramos os registros escritos, os áudios e vídeos em oito horas/aula e os registros de interações no ambiente virtual dos alunos, os quais assinaram termo de consentimento livre e esclarecido autorizando uso dos dados.

Nesta etapa, em que se deu a coleta de parte dos dados da pesquisa, as demais autoras 
do artigo acompanharam as aulas como observadoras, sem de fato interagir com os alunos no desenvolvimento da atividade de modelagem. Além disso, auxiliaram nas análises empreendidas, considerando uma abordagem qualitativa de cunho interpretativo (BOGDAN; BIKLEN, 1994).

\section{Modelagem Matemática}

Dentre as tendências da Educação Matemática, a Modelagem Matemática pode se configurar como uma alternativa pedagógica na qual se busca uma solução para um problema definido a partir de uma situação que, de forma geral, se encontra no contexto não matemático. É nesse sentido que Cirillo et al. (2016, p. 6) afirmam que "a razão básica para modelar com a matemática é entender a realidade, ou algo sobre o mundo real”. Em um ambiente educacional, entender algo sobre o mundo real via lentes matemáticas se faz a partir de uma representação simplificada do fenômeno em estudo (D’AMBROSIO, 2015).

No contexto de uma situação-problema, esse entender o mundo real para então fazer simplificações e trazê-lo ao mundo matemático pode exigir alta demanda cognitiva e isso coloca a Modelagem como uma atividade de natureza complexa (BROWN; IKEDA, 2019). Bleiler-Baxter, Barlow e Stephens (2016, p. 57) consideram a simplificação um processo "crítico para que os alunos possam produtivamente avançar no mapeamento de relações matemáticas na situação".

Estamos de acordo com Almeida e Silva (2017) de que a Modelagem Matemática, nos diferentes níveis de escolaridade e em diferentes cursos e disciplinas pode ser usada para aplicação e para a aprendizagem da Matemática. Com isso, nosso interesse em implementar Modelagem Matemática em aulas está pautado em discutir sobre algo que não é propriamente do contexto matemático, mas que necessita de uma compreensão matemática, possibilitando sua aprendizagem. Para isso, temos nos fundamentado em pesquisas que apontam para o potencial da implementação da Modelagem Matemática nas aulas de Matemática (ALMEIDA; VERTUAN, 2014; ARAÚJO; CAMPOS, 2015; BLEILER-BAXTER; BARLOW, 2016; NAFTALIEV, 2017; ALMEIDA; SILVA, 2017; ÄRLEBÄCK; DOERR, 2018; VORHÖLTER, 2018).

Os procedimentos matemáticos que emergem na busca pela solução para o problema são apresentados por meio de símbolos, diagramas, gráficos, expressões algébricas ou geométricas - modelo matemático. Segundo Bassanezi (2002, p. 26), "mesmo que o modelo 
matemático da situação estudada possa ser construído dentro de uma teoria matemática conhecida, ainda assim pode acontecer que as técnicas e métodos matemáticos existentes nesta teoria sejam insuficientes para a obtenção dos resultados desejados".

Almeida e Vertuan (2014, p. 2) assinalam que o modelo matemático "é o que dá forma à solução do problema e a modelagem matemática é a atividade de busca por esta solução". No entanto, podemos considerar, assim como Almeida e Silva (2017, p. 209), que o modelo matemático, enquanto uma estrutura matemática, "deve incorporar, com certo nível de fidelidade, características essenciais do fenômeno que pretende representar". De forma geral:

Os modelos iniciais dos alunos (ou sistemas conceituais) muitas vezes não são muito sofisticados ou úteis, mas esses modelos inicialmente elicitados são avaliados, revisados e refinados à medida que os alunos discutem suas abordagens com outros alunos e compartilham suas interpretações e representações com toda a classe (ÄRLEBÄCK; DOERR, 2018, p. 189).

É nesse sentido, o de revisar e refinar os procedimentos matemáticos que emergem de uma atividade de modelagem, que a literatura da área tem defendido o trabalho em pequenos grupos para, em seguida, participarem de uma discussão com os demais colegas (ÄRLEBÄCK; DOERR, 2018). Ao investigar sobre competências de Modelagem Matemática a partir de estratégias metacognitivas, Vorhölter (2018, p. 344) defende que "trabalhar colaborativamente em grupos requer planejamento conjunto dos processos de modelagem". Quando isso ocorre, a autora afirma que os alunos podem fazer uso de estratégias que suavizam o processo de Modelagem, estratégias que regulam o momento em que os problemas se fazem presentes e estratégias que ajudam a avaliar todo o processo de Modelagem, promovendo competências de Modelagem.

Naftaliev (2017) investigou como alunos, trabalhando em grupos em uma mesma atividade de modelagem matemática, interpretam diagramas interativos que representam movimento de uma corrida a pé. A partir das análises das interações entre os alunos nos grupos, inferiu-se que o "conhecimento foi compartilhado quando os alunos se engajaram em uma atividade reflexiva sobre o raciocínio e os instrumentos utilizados pelos diferentes membros do grupo envolvidos no processo colaborativo" (NAFTALIEV, 2017, p. 553). Isso vai ao encontro das assertivas de Ärlebäck e Doerr (2018, p. 189) de que é por meio das interações que "os alunos aprendem simultaneamente matemática e desenvolvem suas proficiências na modelagem de situações problemáticas”.

Em nossa investigação estamos interessadas em evidenciar aspectos da aprendizagem colaborativa, caracterizados na próxima seção, que se mostram quando os alunos, trabalhando em grupo, definem um problema, realizam uma abordagem matemática e obtêm 
uma solução no desenvolvimento de uma atividade de modelagem matemática que emergiu de uma tarefa proposta em um ambiente virtual de aprendizagem.

\section{Aprendizagem Colaborativa}

Embora possamos encontrar distintas definições para aprendizagem colaborativa, nos pautamos em autores como Dillenbourg (1999), Correa (2000), Torres, Alcantar e Irala (2004), a partir dos quais expressamos como a consideramos em nossa pesquisa.

Aprendizagem colaborativa é um constructo que se origina de diferentes abordagens conhecidas na literatura como: grupos de aprendizagem, comunidades de aprendizagem, aprendizagem por pares, aprendizagem cooperativa, entre outras. Dentre os aspectos comuns que tais abordagens preservam destaca-se o trabalho em pequenos grupos.

Para Torres, Alcantar e Irala (2004, p. 131), no contexto de ensino, a “aprendizagem colaborativa é uma estratégia de ensino que encoraja a participação do estudante no processo de aprendizagem e que faz da aprendizagem um processo ativo e efetivo". Os autores indicam que a aprendizagem colaborativa se dá a partir do trabalho conjunto dentro de um grupo, sem distinção hierárquica, em um esforço coordenado para atingir um objetivo comum.

São as atividades que dão sentido às ações do grupo. Nesse sentido, a gestão destas atividades envolve os sujeitos de modo que se organizam, definem funções, discutem ideias e posições, interagem entre si, definem subtarefas, a partir de uma proposta elaborada, definida e negociada coletivamente (TORRES; ALCANTAR; IRALA, 2004).

Dillenbourg (1999), Stahl, Koschmann e Suthers (2006) e Correa (2000) levam em conta a presença de tecnologias digitais e da Internet ao discutir a aprendizagem colaborativa. A denominada CSCL (Computer Supported Collaborative Learning ou Aprendizagem Colaborativa Assistida por Computador) pode ser definida como "uma estratégia de ensino e aprendizagem pela qual dois ou mais sujeitos interagem para construir conhecimento, por meio de discussão, reflexão e tomada de decisão, um processo no qual os recursos do computador atuam como mediadores" (CORREA, 2000, p. 7). Segundo Stahl, Koschmann e Suthers (2006), a CSCL pode considerar a forma de interação a distância ou face a face, tanto síncrona quanto assincronamente.

Para definir interações colaborativas, Dillenbourg (1999) elenca interatividade, sincronicidade e negociabilidade como critérios cruciais. A partir desse autor, Correa (2000) pauta que a aprendizagem colaborativa requer relações de trabalho no grupo com 
características de interatividade, sincronia na interação e negociação.

Interatividade: a aprendizagem se dá na intervenção entre dois ou mais sujeitos, mediada por trocas de opiniões e pontos de vista. "A importância dessa interação não está na quantidade de trocas e intervenções que ocorrem, mas no grau de influência que a interação tem no processo cognitivo e de aprendizagem do colega" (CORREA, 2000, p. 6).

Sincronia na interação: tanto a interação síncrona quanto a assíncrona são significativas para a aprendizagem. Um primeiro momento síncrono, em que os sujeitos retroalimentam um diálogo com respostas imediatas permite que as palavras de um desencadeiem novas ideias e respostas para o outro. Segundo Correa (2000, p. 6), a colaboração "é uma atividade coordenada e síncrona, que surge como resultado de uma tentativa contínua de construir e manter uma concepção compartilhada de um problema". No entanto, para a autora, além de a construção do conhecimento ser um processo social, tem também “caráter individual de reflexão e internalização, que valida o espaço de comunicação assíncrono. É nele que se pode expressar os resultados amadurecidos pessoalmente, e não apenas como resultado de um diálogo interativo" (CORREA, 2000, p. 6).

Negociação: processo pelo qual os sujeitos buscam obter acordos em relação a uma ideia, tarefa ou problema. Da interação colaborativa decorre a negociação de significados que pode levar ao surgimento de entendimento mútuo. Nesse caso, um sujeito não deve impor sua visão por meio da autoridade, mas tem o desafio de argumentar de acordo com seu ponto de vista, justificar, negociar e tentar convencer seus pares. "A estrutura do diálogo colaborativo é mais complexa do que a estrutura do diálogo tutorial. [...] a negociação que ocorre no diálogo não é um tipo de sequência isolada, mas é um processo adequado e constitutivo de qualquer diálogo" (CORREA, 2000, p. 6).

Quando Brown e Ikeda (2019) alegam que os alunos precisam aprender a trabalhar em grupo e aprender a fazê-lo em colaboração, também apontam que isso representa um desafio adicional quando, além de aprender a trabalhar em colaboração, o fazem durante o desenvolvimento de uma atividade de Modelagem. Isso se caracteriza como um desafio, segundo os autores, pois, em aulas de Matemática os alunos são pouco estimulados a trabalhar colaborativamente e, em geral, a Modelagem não é parte da prática pedagógica escolar.

Como, de forma geral, na literatura em Modelagem Matemática não estão explícitas orientações sistemáticas para o trabalho em grupos, assumimos as orientações de Torres, Alcantar e Irala (2004, p. 142) - aula de grupos de consenso. Em aula de grupos de consenso: 


\begin{abstract}
as pessoas trabalham colaborativamente numa tarefa ou atividade, negociando entre si o que acreditam e sabem para alcançar algum tipo de consenso ou acordo. $\mathrm{Na}$ organização destes grupos, os professores geralmente: (a) dividem a turma em grupos pequenos (de dois a seis participantes, dependendo da tarefa); (b) providenciam uma tarefa, previamente definida, para os grupos pequenos; (c) reagrupam a turma em uma sessão plenária para ouvir os relatos dos grupos pequenos e negociar com o grupo todo; e (d) avaliam a qualidade do trabalho dos estudantes.
\end{abstract}

Na próxima seção trazemos uma análise, a partir da descrição do desenvolvimento da atividade de Modelagem sobre a secagem de uma toalha.

\title{
5 Análise da atividade desenvolvida
}

Para o desenvolvimento da atividade, no primeiro encontro, a professora solicitou, como forma de se inteirarem da situação-problema, que os grupos discutissem como coletariam dados sobre o processo de secagem de uma toalha (mesma problemática abordada na primeira proposição da atividade avaliativa). Ainda nesse encontro, cada grupo expôs suas estratégias em uma plenária e percebeu-se que os grupos dariam encaminhamentos similares. Entretanto, a professora havia antecipado a coleta de $\operatorname{dados}^{1}$ e entregou a cada grupo cópia de uma planilha com três conjuntos de dados a partir dos quais deveriam definir um problema para estudar e se dedicar trabalhando de forma colaborativa, interagindo entre os colegas de grupo e com a professora.

A Figura 2 apresenta o primeiro conjunto de dados, que se refere à perda de massa de uma toalha lavada e centrifugada colocada para secar em um ambiente interno, sem incidência de vento, no período da manhã. Além de informações sobre a massa, foram registradas informações climáticas obtidas de sites especializados. O segundo conjunto de dados se refere à mesma toalha levada ao ambiente externo, mas sem a incidência de irradiação solar; e o terceiro quando a toalha foi novamente levada ao ambiente interno. Em todas as situações a forma como a toalha foi estendida e manipulada para a pesagem foi preservada.

\footnotetext{
${ }^{1}$ A coleta de dados não era foco da investigação devido a inviabilidade da coleta ser feita em aula regular para esse curso que é noturno.
} 


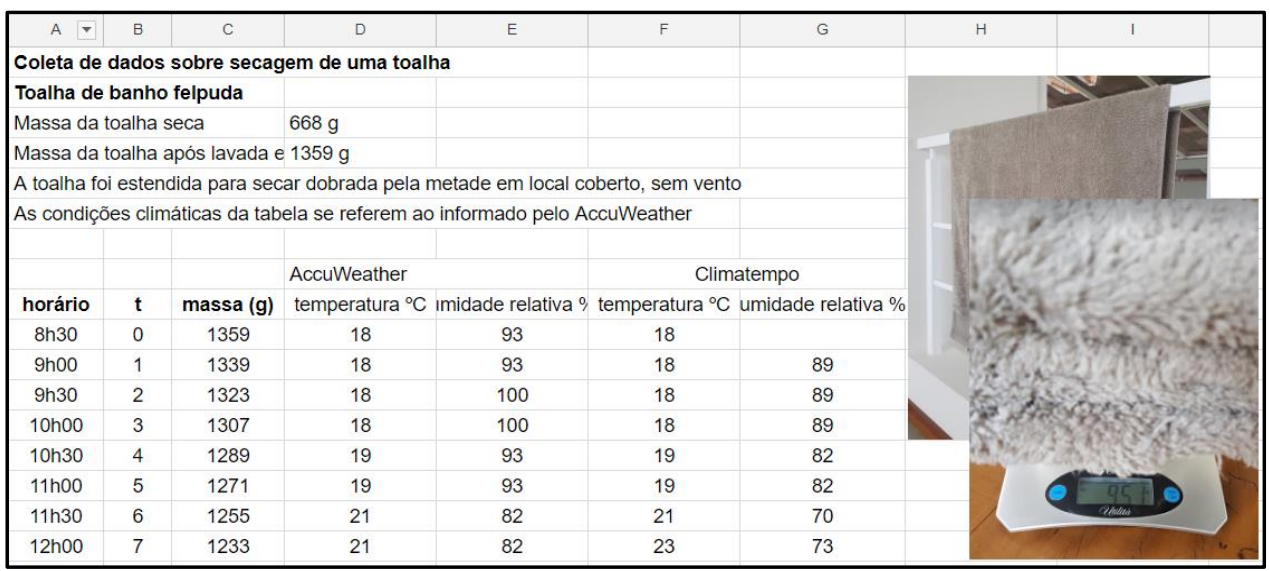

Figura 2 - Primeiro conjunto de dados

Fonte: Arquivo da Professora (2018)

No segundo encontro, a professora orientou que os grupos dessem sequência às discussões buscando uma solução para o problema definido e, no encontro seguinte, comunicassem à turma, para, a partir de discussões com demais colegas e intervenção da professora, promover a sistematização dos conceitos matemáticos. Tal sistematização se deu no quarto encontro. Esse encaminhamento seguiu as orientações de Torres, Alcantar e Irala (2004).

Embora todos os grupos tenham trabalhado de forma comprometida e tenham obtido uma solução para o problema que cada qual propôs, para este artigo, analisamos os registros do Grupo B. Por meio dos vídeos pudemos inferir o que se mostra da aprendizagem colaborativa no que diz respeito ao entendimento e simplificação da situação problemática, à matematização e à solução. Essas inferências são subsidiadas pela interatividade, pela sincronia na interação e pela negociação (CORREA, 2000).

\subsection{Entendimento e simplificação da situação problemática}

Com a solicitação da professora para descreverem os procedimentos, os alunos interagem com o intuito de se chegar a um consenso no qual simplificam a situaçãoproblema, decidindo desconsiderar a temperatura ambiente e que o foco de seu problema seria a secagem da toalha ao ar livre, conforme transcrição:
E: Você pega a toalha seca e pesa, ai
é um quilo, entendeu? você molha e novamente pesa. A cada J: Aham.
duas horas você vai repetindo,
$R$ : Eu acho que pode considerar a cada repetindo.
J: Você vai ter que ver o recipiente que vai colocar. meia hora.
E: Não... você molha ela e pesa. É que J: Acho que meia hora dá. O clima não influencia né?
o peso da água é um para um, um litro
E: Na verdade, ele está desconsiderando. $J$ : É porque influencia bastante. 
T: É, depende da temperatura.

$E$ : Na verdade, sabe o que seca mais rápido?

T: Não.

E: $O$ vento seca mais rápido do que a temperatura.

F: Não sabia!

T: Ao meio dia, a temperatura foi

de... Será que vamos usar todos os dados? Umidade com temperatura, com tudo?

$R$ : Acho que tempo por quantidade de água!

E: Vamos falar que estamos desconsiderando a temperatura ambiente. $J$ : Vou anotar, então.

$R$ : Vai ser ao ar livre né?

(Diálogo interativo entre alunos, 2018).

Podemos evidenciar que esse momento de interações síncronas (CORREA, 2000), elementos que influenciam no fenômeno da secagem da toalha (o clima, o vento e a temperatura) são discutidos e compreendidos pelos integrantes do grupo. Além disso, por meio das interações, os alunos negociam a simplificação da situação a ser investigada (desconsiderando a temperatura ambiente). De acordo com Bleiler-Baxter, Barlow e Stephens (2016), a simplificação pode ser considerada um processo crítico e se constitui em um mapeamento para orientar o encaminhamento da atividade. A negociação possibilita o surgimento de entendimento mútuo. Inicialmente algumas perguntas parecem refletir insegurança (O clima não influencia né?; Será que vamos usar todos os dados?; Umidade com temperatura, com tudo?), no entanto, as respostas imediatas dos colegas despertam novas ideias e respostas a novas perguntas nos demais, o que indica sincronia na interação.

É por meio da interação que a simplificação da situação ocorre, quando entendem que, embora o vento tenha influência no fenômeno seria necessário restringir as variáveis e assim decidiram considerar o tempo e a quantidade de água na toalha, reconhecendo que um quilograma de água, corresponde a um litro

Por meio da simplificação, os alunos se engajam na formulação de um problema a ser investigado. Essa ação está em consonância com as afirmações de Almeida, Silva e Vertuan (2012, p. 16), de que a formulação do problema "requer que alguns aspectos já sejam conhecidos" (É que o peso da água é um para um, um litro é um quilo) ou mesmo venham a se tornar conhecidos. O grupo, então, define o problema a ser investigado e que está relacionado ao tempo em que a toalha leva para secar (Figura 3).

Problema: Quanto tempo leva para una toalha entrifugada secar

em um ambiente aberto com a trigo do sol?

Figura 3 - Definição do problema do Grupo B, após análise dos dados Fonte: Relatório dos alunos (2018) 


\subsection{Matematização e solução}

Nas interações captadas pelos vídeos, parece haver um entendimento do grupo que se deva encontrar um modelo para descrever a situação. Enquanto E e R analisam a planilha de dados que receberam e de imediato recorrem a dois softwares (Excel e Curve Expert) para representar os conjuntos de dados graficamente, $\mathrm{T}$ e $\mathrm{F}$ acessam o arquivo no ambiente virtual e observam as variações na massa com o passar do tempo nos diferentes ambientes, recorrendo à calculadora (Figura 4). Tratam-se de ações em que a "busca e elaboração de uma representação matemática são mediadas por relações entre as características da situação e os conceitos, técnicas e procedimentos matemáticos adequados para representar matematicamente essas características" (ALMEIDA; SILVA; VERTUAN, 2012, p. 16) - a matematização.

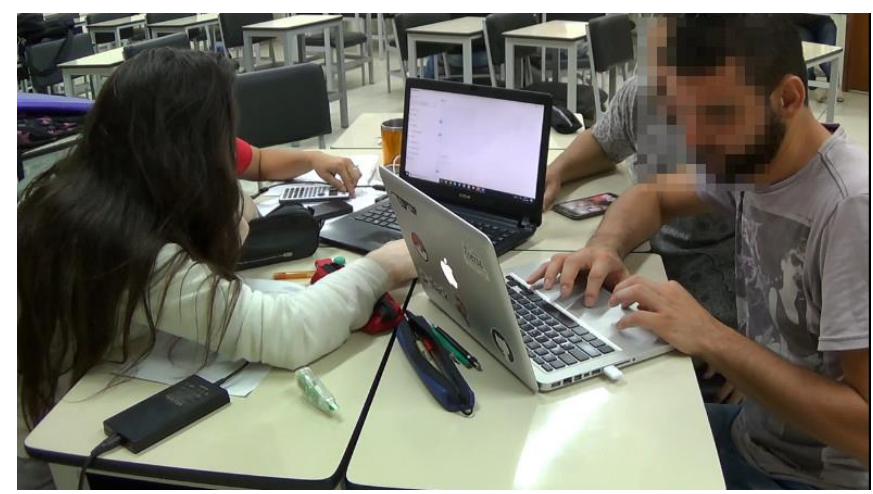

Figura 4 - Alunos durante análise dos dados da planilha Fonte: Registro de vídeo na matematização (2018)

Com auxílio de softwares e da calculadora, os alunos vislumbraram um modelo matemático que pudesse representar algebricamente a situação. No desenvolvimento de uma atividade de Modelagem Matemática, fazer um ajuste de curva por meio de um software envolve "processos perceptivos para o reconhecimento de padrões gráficos" (HALL; LINGEFJÄRD, 2017, p. 444). Esse reconhecimento foi conduzido por interações e negociações entre os alunos, conforme transcrição:

E: A massa vai ser em $x$, né? [manipula os dados no Curve Expert, mas não consegue]. Não, abandona esse aqui [em referência ao Curve]. Ai eu sei mexer [trocando de computador com dados no Excel].

[...]

R: Agora a gente precisa pedir a linha de tendência.

F: É... a linha de tendência.
E: Adicionar linha de tendência. De que tipo ela é? Está quase linear.

R: Mas ela tem uma taxa de decaimento.

E: Mas a gente tem que escolher o tipo de equação.

R: Polinomial.

E: Não é polinomial.

T: Espera aí, deixa eu ver.

E: Que tipo de equação que é pra decaimento? 
R: Tinha que ser exponencial.

T: Exponencial.

R: Ela não está dando opção de exponencial?

T: Mas na verdade, aqui você tinha que colocar o tempo [referindo-se à coluna da variável independente]. [...]

$F$ : Tinha que mudar o eixo.

$J$ : É verdade, faz com o tempo no eixo $x$. [...]

$R$ : Esse aí ficou bem melhor.
$J:$ É ficou melhor.

$[\ldots]$

$R:$ É uma exponencial, porque é o decaimento da exponencial, né? É decaimento exponencial.

T: Olha, como é o decaimento exponencial [mostrando uma pesquisa que fez no celular]. Porque não está parecendo exponencial.

(Diálogo interativo entre alunos, 2018).

Em um primeiro momento os alunos optaram por usar o software Excel para identificar um modelo que melhor se ajustasse aos dados, deliberando os valores das variáveis dependente e independente. A primeira ação foi de considerar a massa (em g) como uma variável independente. Com essa decisão um impasse foi gerado para a escolha da linha de tendência na qual diferentes modelos poderiam "dar forma" à situação investigada - linear, polinomial, exponencial. Ao ouvirem as considerações de $\mathrm{T}$ e de $\mathrm{F}$, os alunos alteram os encaminhamentos, considerando a massa (em g) dependente do tempo (em minutos), o que auxiliou na tomada de decisão para a escolha de um modelo exponencial. Essa decisão está pautada na interação entre os alunos em que analisaram os dados e discutiram os resultados encontrados. Isso está de acordo com Correa (2000) e Torres, Alcantar e Irala (2004), segundo os quais da interação colaborativa decorre a negociação de significados que pode levar ao surgimento de entendimento mútuo e consenso.

Percebemos que o grupo lançou mão do suporte computacional, assim, a colaboração foi mediada por tecnologias digitais que auxiliaram tanto nas diferentes representações dos dados a partir de softwares quanto na obtenção de informações pela Internet. De acordo com Stahl, Koschmann e Suthers (2006, p. 3), "a aprendizagem com suporte computacional nem sempre se manifesta por meio da comunicação online; pode envolver, por exemplo, uma simulação computacional de um modelo científico ou de uma representação interativa compartilhada".

Embora os colegas alegassem que o adequado seria o modelo exponencial, $\mathrm{R}$ só abandonou a opção polinomial após refletir sobre uma intervenção da professora, quando a consultou sobre o comando que deveria usar para igualar a função polinomial a zero em um aplicativo on-line (https://wolframalpha.com), e assim identificar o tempo necessário para que a toalha estivesse seca, conforme transcrição:

R: Então professora... deu uma função polinomial de grau 4, na verdade.
R: Para saber quando a toalha vai estar seca, depois de quantas horas eu posso tirar a toalha. 
P: Tá, e o que vocês levaram em conta para escolher essa função? [...]

$R$ : A gente usou... os dados, eu joguei no Curve. Daí ele deu várias equações e essa que eu escolhi, no caso, é a que mais se encaixa nos pontos [...].

$P:$ E com essa equação você... ela pode ser útil para que finalidade?
P: Tá. Então, veja quanto tempo precisaria, ou isso vocês já fizeram? $R$ : Não, mas isso é só igualar a zero. $P$ : Mas, ao igualar a zero vocês não poderiam obter mais de uma solução? Pense sobre o que isso indica!

(Diálogo interativo entre professora e alunos, 2018).

$\mathrm{Na}$ comunicação dos resultados para a turma (Figura 5), o aluno $\mathrm{R}$ demonstrou ter refletido sobre a intervenção da professora e ter compartilhado com o grupo sua constatação:

R: Eu acabei jogando os dados no Curve para ver e deu essa equação aqui polinomial. A gente até debateu aqui. [...] ai eu joguei essa equação no Wolfram e tentei igualar só que eu vi que, por ser uma função polinomial, ela tem algumas raizes, e ela pode repetir. Tipo, dois pontos que ela pode dar o valor inicial da toalha, então não ficava muito viável. E aí a gente começou a debater na equação... exponencial (Comentários do aluno R, 2018).
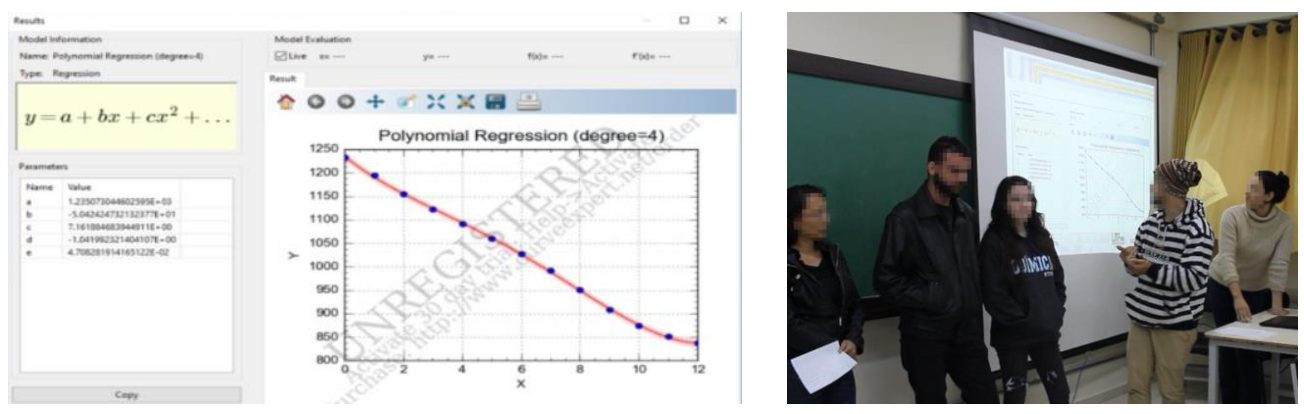

Figura 5 - R falando sobre dedução do modelo na comunicação dos resultados Fonte: Registro de vídeo na comunicação (2018)

Com a manifestação do aluno R evidenciamos que foi fundamental o tempo entre a interação síncrona com os colegas do grupo, a intervenção da professora (ao igualar a zero vocês não poderiam obter mais de uma solução? Pense sobre o que isso indica!) e o momento em que permaneceu isolado do grupo, interagindo apenas com recursos digitais (aí eu joguei essa equação no Wolfram e tentei igualar só que eu vi que, por ser uma função polinomial, ela tem algumas raízes [...]). Nesse intervalo de tempo, o mesmo pode ter refletido sobre o que havia considerado adequado como modelo (função polinomial) e o que os demais colegas de grupo defendiam (modelo exponencial). O que podemos conjecturar é que, além da interação com os colegas, a intervenção de alguém externo ao grupo, no caso a professora, de certo modo convenceu $\mathrm{R}$, seja pelo uso de argumentos ainda não apresentados pelos colegas, seja pelo fato de $\mathrm{R}$ ter aceitado a sugestão considerando a "autoridade" da professora. No entanto, as evidências se fundamentam no fato de que $\mathrm{R}$ não aceitou de imediato, mas mobilizou recursos que, a seu ver, inviabilizaram a validação do modelo polinomial. 
Isso está em consonância com o que expressa Correa (2000, p. 6) com relação a uma fase mais reflexiva, pertencente ao mundo individual. Segunda a autora, "nesse estágio de reflexão do aprendizado colaborativo, a comunicação assíncrona entra em jogo".

$\mathrm{O}$ aluno $\mathrm{R}$ fica convencido de que uma função polinomial de quarto grau não representa o fenômeno pelas características matemáticas do mesmo com relação ao número de raízes e externaliza esse convencimento na comunicação dos resultados para o restante da turma. Segundo Brown e Edwards (2011, p. 187), “[...] a comunicação dos alunos acerca de suas soluções para atividades de modelagem, dá uma visão da profundidade de suas compreensões matemáticas e como eles utilizam o conhecimento prévio do contexto de uma atividade na sua solução”.

Abusca pelo modelo e solução do problema foram intermediados por recursos digitais e, embora a curva de tendência dos três conjuntos de dados não tivesse o aspecto característico de uma curva exponencial, podendo ser mais assemelhado com um comportamento linear, até certo ponto não estava explícito, porque o grupo alegava ser um decaimento exponencial. Os recursos digitais aproximam a representação gráfica de "processos conceituais que traduzem os atributos visuais em questão, tais como quantidades, escalas e símbolos para conceitos relevantes" (HALL; LINGEFJÄRD, 2017, p. 444). Todavia, não levam em consideração o fenômeno em estudo.

No entanto, as falas observadas em áudio indicam que T reconhecia o comportamento do fenômeno, considerando a taxa de variação da quantidade de água proporcional à quantidade, embora tenha sido ignorada por E e R inicialmente. Quando passaram a discutir aspectos dos dados e levaram em conta as colocações de T evidenciamos, a partir da sincronia das interações e da negociação, que o grupo teve melhoria na compreensão e chegaram a resultados mais coerentes, conforme transcrição a seguir:

T: Dai essa é a quantidade de água, aqui é o tempo [apontando a folha] e essa é a constante de proporcionalidade. E a EDO fica [e vai anotando] $d y / d x$ igual a $k$ vezes $y$, $e$ a solução dela é y igual a [anotações da Figura 7]... é a solução da exponencial?! Acho que é isso né, do decaimento.

J: Que estranho.

T: Fala que tá estranho, vamos pesquisar... [pega seu celular] acho que tem aqui no Moodle. [...]

$F: \quad E$, a gente ia desconsiderar a temperatura mesmo, né? Considerar o tempo e a água.

E: Isso tá na constante né.

T: Está tudo envolvido aqui ó [apontando a constante $k$ ], a umidade e tudo.

E: Verdade.

(Diálogo interativo entre alunos, 2018).

Mesmo que os integrantes do grupo aparentassem um consenso na dedução do 
modelo matemático $\left(y(x)=691 e^{-0,02 x}\right.$, Figura 7 , em que $x$ representa o tempo em minutos e $y$ a quantidade de água em mililitros), a negociação ainda ocorreu durante a comunicação dos resultados para a turma (Figura 8), momento da plenária indicado na proposta de Torres, Alcantar e Irala (2004), a partir de intervenções da professora:

P: Qual que era a ideia de vocês? Era responder o que? Estudar o que?

F: Em quanto tempo essa toalha ficaria completamente seca.

E: No Excel, a gente colocou a linha de tendência do nosso gráfico. Ai o Excel nos dá uma equação exponencial. Aqui ele assume, esses valores aqui são assumidos como o peso da toalha ainda e ele nos dava essa constante de proporcionalidade [apontando para a projeção (Figura 6)]. Ai utilizando essa função aqui, a gente consegue os valores que a gente tem na nossa tabela.

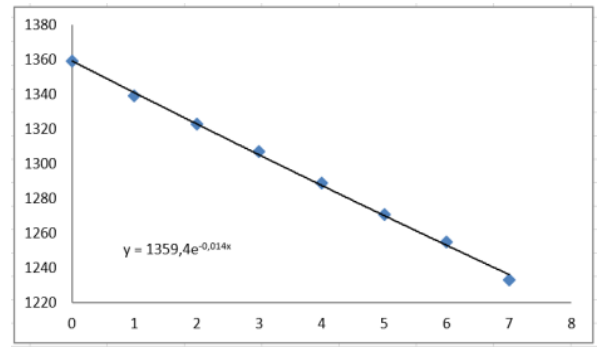

Figura 6 - Gráfico mencionado por E Fonte: arquivo digital, Grupo B (2018)

P: Vocês chegaram a revisar?

E: Uhum. Aí, em seguida a gente retirou esse valor [apontando para a projeção] e trabalhamos entorno dessa constante de proporcionalidade [...]

$y(x)=691 e^{k x}$
$d t=k y \quad y(1)=671=691 e^{k}$
$y 0=691 e^{k t}$
$\frac{671}{691}=e^{k}$
$\ln 00,971=\ln e^{k}$
$k \cong-902$

Figura 7 - Parte da resolução do Grupo B Fonte: Recorte dos registros do Grupo B (2018)
$P:$ E conseguiram?

E: Aham.

[...]

P: O que leva vocês a pensarem que de fato esse $k$ representa... o que está por trás?

E: Ah, eu estava pensando que por ela, a toalha estar num mesmo ambiente, a gente não considerou as variações desse ambiente, que a gente considera que está dentro desse $k$, ai por isso que eu acho, que eu acredito que esse $k$ esteja proporcional para todos esses dados que foram coletados. [...]

T: Vai mudar, se a gente colocar um outro valor, aqui também vai mudar.

$R$ : Mas não, porque esse $k$ é uma constante para todos os valores. [...]

T: A gente não testou.

$R$ : É porque... é assim professora, como a gente pegou o valor da nossa curva, que é dessa equação da nossa curva, então qualquer ponto que a gente pegar da nossa curva, esse $k$ vai ser igual, ele não pode mudar [...]

E: Ai por fim a gente chegou a um tempo estimado pra secagem da toalha. Com a equação a gente conseguiu chegar em 35 horas e 32 minutos.

(Diálogo interativo entre professora e alunos, 2018).

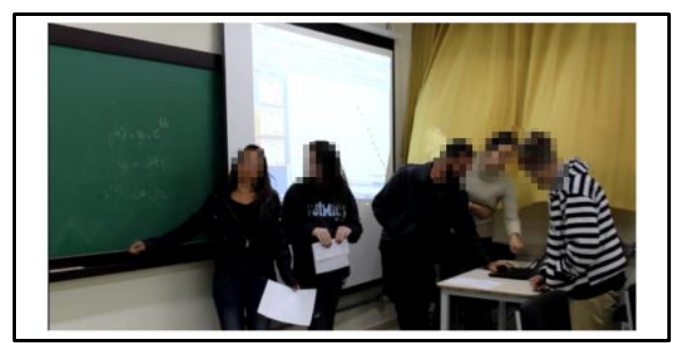

Figura 8 - Comunicação para a turma Fonte: Registro de vídeo da apresentação (2018)

Observa-se no fim desta interação que a professora instigou os alunos sobre a validade da metodologia aplicada para determinar o valor da constante $k$. Este ato fez com que, ao término da apresentação, os alunos estivessem convencidos de que precisariam rever valores 
usados para determinar a constante de proporcionalidade $k$. A professora promoveu uma interação colaborativa de modo que suas intervenções a partir de questionamentos levassem os alunos a argumentarem segundo seus pontos de vista para tentar convencer seus pares. Nesse caso, o intuito da professora era se valer da interação síncrona para promover negociação.

A última etapa da proposta de Torres, Alcantar e Irala (2004) deve receber atenção, qual seja: avaliar a qualidade do trabalho dos estudantes. Quanto ao Grupo B, pode-se observar que o objetivo de obter uma solução para o problema por eles elaborado foi alcançado: "Quanto tempo leva para uma toalha centrifugada secar em um ambiente aberto com abrigo do sol?". Embora nossa análise tenha mostrado que o grupo foi construindo um resultado colaborativamente e a notória influência da interatividade para obtenção de um consenso, a avaliação se deu levando em conta o propósito da professora com a atividade de Modelagem: que os alunos compreendessem a situação-problema a partir de uma equação diferencial ordinária.

\section{Considerações finais}

Atividades de Modelagem Matemática em sala de aula têm o trabalho em grupo como aporte. $\mathrm{Na}$ literatura existem pesquisas que articulam atividades de Modelagem Matemática com o trabalho colaborativo, porém, em geral as pesquisas não deixam explícita a metodologia empregada para caracterizar a colaboração, o trabalho colaborativo, a aprendizagem colaborativa.

Neste artigo, buscamos evidenciar o que se mostre de aprendizagem colaborativa no desenvolvimento de uma atividade de Modelagem Matemática quando os alunos são orientados a fazê-lo em colaboração.

Observamos que, no desenvolvimento da atividade analisada nesse artigo, as interações efetivadas possibilitaram que mais de uma voz fosse ouvida e considerada, ao mesmo tempo que os alunos realizam investigações, correndo riscos e considerando o outro como um colaborador.

A análise dos dados do Grupo B permitiu evidenciar os aspectos interatividade, sincronia na interação e negociação da aprendizagem colaborativa no desenvolvimento da atividade de Modelagem em relação ao entendimento e simplificação da situação problemática, à matematização e à solução. 
Diante de uma situação-problema a ser investigada pelos integrantes do grupo, a simplificação do que de fato seria estudado culminou na definição de um problema. Para isso, houve interatividade para escolher os dados que deveriam utilizar (secagem da toalha ao ar livre), bem como negociação quanto às variáveis que seriam analisadas (quantidade de água, em gramas, em função do tempo, em minutos).

Com o problema definido, os alunos consideraram hipóteses sobre os dados para, então, deduzir um modelo matemático. A matematização foi permeada por interatividade e negociação mediadas por tecnologias digitais, tais como softwares e consulta à Internet. Considerar as vozes dos outros integrantes do grupo e entender que todos são colaboradores direcionou a escolha do modelo que representava a situação em estudo.

Posto o modelo matemático que melhor representava a situação investigada pelo Grupo B, a resolução foi subsidiada tanto por interações síncronas quanto assíncronas com a intervenção colaborativa da professora. A partir de comunicação, a professora levou o grupo a perceber que, embora o modelo fosse adequado e houvesse a compreensão da situaçãoproblema a partir de uma EDO, havia a necessidade de avançar no significado da constante de proporcionalidade $k$ e cuidados com arredondamentos realizados.

De forma geral, no desenvolvimento da atividade de Modelagem Matemática que investigamos, evidenciamos que os envolvidos se retroalimentam e as palavras de um acionam novas ideias e respostas no outro que, juntos, chegam à solução da situação de forma síncrona. Assim, enquanto os alunos realizam seus procedimentos em grupo, falam a respeito do que fazem, questionando e, diversas vezes, esclarecendo o que estão realizando e suas falas, além de conduzirem a realização da atividade, a orientam, tendo em vista que, ao "se ouvir', o aluno tem a oportunidade de observar um procedimento impreciso ou incorreto e corrigi-lo, realizando uma interação consigo mesmo.

Cientes da existência de resultados de pesquisa que apontam a importância das interações em atividades de Modelagem Matemática, consideramos que nossa investigação traz contribuição para a área de Educação Matemática no que se refere a evidência de aspectos que interferem para aprender de forma colaborativa, orientando os alunos a trabalharem em grupo, seguindo uma metodologia (TORRES; ALCANTAR; IRALA, 2004).

Notamos que orientar os alunos no sentido da aprendizagem colaborativa pode ter despertado nos futuros professores o cuidado com o respeito ao ponto de vista dos colegas, a prática da argumentação para a negociação e a evitar a divisão do trabalho para cumprir o objetivo, o que é prática em muitas situações em que os alunos deveriam trabalhar em grupos, 
mesmo em atividades de Modelagem Matemática. No entanto, a análise pontual realizada não permite afirmar que esta tenha sido a razão, assim, pesquisas prolongadas com diferentes grupos e em diferentes atividades poderiam trazer resultados mais conclusivos. Outra demanda de pesquisas futuras diz respeito a buscar evidências de aprendizagem dos alunos nesse contexto de ensino, buscando interface com pesquisas que discutem a Modelagem Matemática e Teorias de Aprendizagem.

Além disso, há de se dar atenção à negociação dos pequenos grupos com o grupo todo na sessão plenária, bem como avaliar a qualidade do trabalho de todos os grupos. Esse empreendimento pode estar presente na comunicação dos resultados de uma atividade de modelagem em que os grupos podem retomar seus encaminhamentos e alterar o modelo deduzido e a solução do problema. Isso se configura como uma possibilidade de pesquisa futura, assim como as discussões iniciadas neste artigo que podem ser ampliadas no que se refere à importância do momento de sistematização realizado com toda a turma após a comunicação das atividades de Modelagem de cada grupo.

Isso está em consonância com Torres, Alcantar e Irala (2004, p. 142), de que a estratégia instrucional baseada na aprendizagem colaborativa deve prever "a organização, a estruturação e a sistematização dos elementos que compõem as experiências curriculares, a fim de garantir que os alunos sejam conduzidos pelos caminhos adequados que o levem a atingir o objetivo final proposto".

\section{Referências}

ALMEIDA, L. M. W. Um olhar semiótico sobre modelos e modelagem: metáforas como foco de análise. Zetetiké, Campinas, v. 18, número temático, p. 387-414, dez. 2010.

ALMEIDA, L. M. W.; SILVA, K. A. P. A Ação dos Signos e o Conhecimento dos Alunos em Atividades de Modelagem Matemática. Bolema, Rio Claro, v. 31, n. 57, p. 202-219, abr. 2017.

ALMEIDA, L. W.; SILVA, K. P.; VERTUAN, R. E. Modelagem Matemática na Educação Básica. São Paulo: Contexto, 2012.

ALMEIDA, L. M. W.; VERTUAN, R. E. Modelagem Matemática na Educação Básica. In: ALMEIDA, L. W.; SILVA, K. P. (Orgs.). Modelagem Matemática em Foco. Rio de Janeiro: Ciência Moderna, 2014. v. 1, p. 1-21.

ARAÚJO, J. L.; CAMPOS, I. S. Negotiating the Use of Mathematics in a Mathematical Modelling Project. In: STILLMAN, G. A.; BLUM, W.; BIEMBENGUT, M. S. (Eds.). Mathematical Modelling in Education Research and Practice: cultural, social and cognitive influences. New York: Springer, 2015. p. 283-291.

ÄRLEBÄCK, J. B.; DOERR, H. M. Students' interpretations and reasoning about phenomena with negative rates of change throughout a model development sequence. ZDM Mathematics 
Education, Berlin, v. 50, n.1, p. 187-200, 2018.

BASSANEZI, R. C. Ensino-aprendizagem com modelagem matemática: uma nova estratégia. São Paulo: Contexto, 2002.

BLEILER-BAXTER, S. K.; BARLOW, A. T.; STEPHENS, D. C. Moving beyond context: challenges in modeling instruction. In: NCTM. Mathematical Modeling and Modeling Mathematics. USA: APME, 2016. p. 53-64.

BOGDAN, R; BIKLEN, S. Investigação Qualitativa em Educação: uma introdução à teoria e aos métodos. Porto: Porto Editora, 1994.

BROWN, J.; EDWARDS, I. Modelling tasks: insights into mathematical understanding. In: KAISER, G.; BLUM, W.; FERRI, R. B.; STILLMAN, G. (Orgs.). Trends in teaching and learning of mathematical modeling. New York: Springer, 2011. p.187-197.

BROWN, J. P.; IKEDA, T.. Conclusions and Future Lines of Inquiry in Mathematical Modelling Research in Education. In: STILLMAN, G. A.; BROWN, J. P. (Orgs.). Lines of Inquiry in Mathematical Modelling Research in Education. Cham: Springer International Publishing, 2019. p. 233-253. DOI: 10.1007/978-3-030-14931-4_13. Disponível em: https://doi.org/10.1007/978-3030-14931-4_13. Acesso em: 20 dez. 2019.

CIRILLO M.; PELESKO, J. A.; FELTON-KOESTLER, M. D.; RUBEL, L. Perspectives on modeling in school mathematics. In: NCTM. Mathematical Modeling and Modeling Mathematics. USA: APME, 2016. p. 3-16.

CORREA, L. M. Z. Aprendizaje Colaborativo: una nueva forma de diálogo interpessoal y en red. Quaderns Digital, Valência, v. 1, n. 27, p. 1-10, 2000.

D'AMBROSIO, U. Mathematical Modelling as a strategy for building-up systems of knowledge in different cultural environments. In: STILLMAN, G. A.; BLUM, W.; BIEMBENGUT, M. S. (Eds.). Mathematical modelling in education research and practice: Cultural, social and cognitive influences. Cham: Springer, 2015. p. 173-183.

DILLENBOURG, P. What do you mean by collaborative learning? In: DILLENBOURG, P. (Ed.). Collaborative - learning: Cognitive and Computational Approaches. Oxford: Elsevier, 1999. p. 119. Disponível em: https://tecfa.unige.ch/tecfa/publicat/dil-papers-2/Dil.7.1.14.pdf. Acesso em: 20 dez. 2019.

HALL, J.; LINGEFJÄRD, T. Mathematical Modeling: applications with GeoGebra. Hoboken: John Wiley \& Sons, 2017.

MORTIMER, E. F.; SCOTT, P. Atividade discursiva nas salas de aula de ciências: uma ferramenta sociocultural para analisar e planejar o ensino. Investigações em Ensino de Ciências. Porto Alegre, v. 7, n.3, p. 283-306, 2002.

NAFTALIEV, E. Interactive Diagrams Used for Collaborative Learning Concerning Mathematical Models of Motion. In: STILLMAN, G. A.; BLUM, W.; KAISER, G. (Eds.). Mathematical

Modelling and Applications: Crossing and Researching Boundaries in Mathematics Education. New York: Springer, 2017. p. 553-563.

STAHL, G.; KOSCHMANN, T.; SUTHERS, D. Computer-supported collaborative learning: An historical perspective. In: SAWYER, R. K. (Ed.). Cambridge handbook of the learning sciences. Cambridge: Cambridge University Press, 2006. p. 409-426. Traduzido por Hugo Fuks e Tatiana 
Escovedo. Disponível em: http://gerrystahl.net/cscl/CSCL_Portuguese.pdf. Acesso em: 20 dez. 2019.

TORRES, P. L. Laboratório on-line de aprendizagem: uma experiência de aprendizagem colaborativa por meio do ambiente virtual de aprendizagem eurek@kids. Cadernos CEDES, São Paulo, v. 27, n. 73, p. 335-352, set./dez. 2007.

TORRES, P. L.; ALCANTAR, P. R.; IRALA, E. A. F. Grupos de Consenso: Uma proposta de aprendizagem colaborativa para o processo de ensino-aprendizagem. Revista Diálogo Educacional, Curitiba, v. 4, n. 13, p. 129-145, set./dez. 2004.

TRONCON, L. E. A. Ambiente educacional. Revista Medicina, Ribeirão Preto, v. 47, n. 3, p. 264$271,2014$.

VERTUAN, R. E; BORSSOI, A. H; ALMEIDA, L. M. W. O papel da Mediação e da Intencionalidade em Atividades de Modelagem Matemática. Revista Eletrônica de Educação, São Carlos, v. 7, n. 3, p. 63-80, set./dez. 2013.

VORHÖLTER, K. Conceptualization and measuring of metacognitive modelling competencies: empirical verification of theoretical assumptions. ZDM Mathematics Education, Berlin, v. 50, n.1, p. 343-354, 2018. 